\title{
Synchronous primary lung cancers: prevalence in surgical material and clinical implications
}

\author{
F A Carey, S C Donnelly, W S Walker, E W J Cameron, D Lamb
}

\begin{abstract}
Background-The prevalence of synchronous primary lung neoplasms in surgical resection specimens was assessed. The associated clinical features and prognostic implications were investigated. Methods-All surgical resections for lung cancer performed during seven years were reviewed. Synchronous tumours were defined by the presence of more than one tumour mass in the lung, by differences in histological subtype, by the presence of separate bronchial origins, or by differences in DNA stemlines. Clinical data were abstracted from case notes and information from the tumour registry.

Results-Just under $2 \%$ of all surgical specimens in the study period contained more than one primary carcinoma. The patients did not differ clinically from the general population of patients having surgery for lung cancer. The overall prognosis was poor (mean survival 27 months) but was significantly better for patients with synchronous squamous carcinomas (mean survival 49 months). Conclusion-Synchronous primary lung carcinomas are associated with a poor prognosis except in patients having tumours only of squamous histological type.
\end{abstract}

(Thorax 1993;48:344-346)

The occurrence of more than one lung cancer in a patient is an unusual event. Most commonly in such patients a second (metachronous) tumour develops after treatment of the initial, presenting carcinoma. ${ }^{12}$ Patients having more than one primary lung carcinoma at presentation (synchronous pulmonary neoplasms) are distinctly less common..$^{3-5} \mathrm{We}$ present a review of the clinical and pathological findings in a series of 19 patients found to have two or more separate primary tumours at the time of lobectomy or pneumonectomy. The study was undertaken with the particular objective of determining the effect such a presentation might have on a patient's prognosis.

\section{Methods}

All resection specimens for lung cancer received in the pathology department of the University of Edinburgh over seven years (1979-85) were retrieved. Reports on the gross anatomy were examined to identify cases in which at least two distinct tumour masses were described by the reporting pathologist. These cases were reviewed histologically. All specimens had been fixed by formalin distension and then sagittally sectioned, thus allowing for full inspection of small airways and the pulmonary parenchyma. Synchronous tumours were distinguished from intrapulmonary metastases by the following criteria. (a) Total physical separation of the lesions within the lung was essential to avoid confusion with carcinomas of mixed differentiation. (b) Distinct tumour masses of different histological subtypes were automatically considered to be synchronous neoplasms. (c) Where all the lesions were squamous carcinomas a synchronous classification was accepted if a separate origin from an area of carcinoma in situ could be identified for each.

A different approach was also used where tumours were of the same histological subtype. Archival paraffin embedded tissue from each lesion was processed for DNA flow cytometry according the standard protocol. ${ }^{67}$ The nuclear suspensions were stained with propidium iodide and analysed on an EPICS CS (Coulter) flow cytometer. At least 10000 nuclei were analysed from each specimen. The resulting DNA histograms were classified as diploid or DNA aneuploid. The latter were defined by the presence of a second $\mathrm{G}_{0} / \mathrm{G}_{1}$ peak on the histogram differing in channel number from the diploid peak by at least $10 \%$. Only histograms with a coefficient of variation of less than 7 on the diploid peak were accepted for analysis. Patients with differences in DNA index between distinct tumour masses were accepted as having synchronous tumours.

Details of smoking history and clinical outcome were obtained from the patients' hospital charts and, when necessary, from general practitioners or tumour registry databanks, or both. The preoperative chest radiographs were also reviewed in each case.

\section{Results}

In all, 1029 lobectomies or pneumonectomies for lung cancer were performed in the years under study. More than one distinct tumour mass was identified in 24 cases $(2 \cdot 3 \%)$. Histologically, one patient had three squamous carcinomas, nine patients had two squamous carcinomas, two had two distinct adenocarcinomas, six had squamous and adenocarcinomas, three had squamous and small cell carcinomas, two had squamous and atypical carcinoid tumours (well differentiated neuroendocrine carcinomas), and one patient 
had an adenosquamous carcinoma in combination with a classical carcinoid tumour.

Five patients were excluded from the study by not fulfilling our criteria for tumour synchrony. Three of these were in the group of 10 cases with more than one squamous carcinoma mass as they showed no evidence of separate tumour origins either histologically or on the basis of DNA ploidy. Histologically, distinct origins from bronchial mucosa were seen in five cases, including the patient with three squamous tumours. Intertumour differences in DNA stemlines were detected in four cases, two of which also showed separate bronchial origins. Both patients with two adenocarcinomas at presentation were excluded as the DNA histograms were identical in the two lesions in each case. The synchronous tumours were all separated by at least $1 \mathrm{~cm}$ macroscopically. They were located within the same lobe in 11 cases and in different lobes of the same lung in eight.

The clinical and pathological data on the 19 patients accepted as having true synchronous pulmonary carcinomas are summarised in the table. The age and sex distributions of these patients are reasonably typical of the population presenting with operable lung cancer in south east Scotland. ${ }^{8}$ One patient was a non-smoker and the others were or had been moderate to heavy smokers. Standard TNM staging was performed in each case by correlation of radiological, operative, and pathological findings. ${ }^{9}$ Preoperative posteroanterior and lateral chest radiography, bronchoscopy, barium swallow examination, and diaphragmatic screening were performed as a routine. Mediastinoscopy and computed tomography were not thought to be indicated in any of the patients. The possibility that the pulmonary lesions might represent metastases from tumours at other sites was excluded clinically so far as possible. None of the patients subsequently developed evidence of such disease. In no case had the possible diagnosis of two tumours been made on the basis of the preoperative chest radiographs.

Follow up data were obtained for all 19 cases (table). Regrettably no postmortem examinations were carried out. There were two perioperative deaths (within 30 days of surgery). The mean survival for the remaining patients was 27 (range 4-100) months. There was no clinical or radiographic evidence of tumour recurrence at the time of death in five of the 17 patients dying after the perioperative period. Three of these patients died of myocardial infarction and two of bronchopneumonia (table). When the cases were grouped by histological subtype a striking difference in outcome was noted between those patients with synchronous tumours all of squamous type (mean (SD) survival 49 $(27 \cdot 8)$ months) and those having any other combination (mean survival $16 \quad(12.8)$ months). The difference between these means reaches statistical significance (Student's $t$ test, $\mathrm{p}<0.01$ ). Four of the five patients dying without evidence of tumour were had synchronous squamous carcinomas which further emphasises the less aggressive nature of this tumour.

\section{Discussion}

The occurrence of more than one carcinoma in an organ is an almost inevitable consequence of the effect of carcinogens causing tumour progression in an epithelium through the stages of dysplasia, carcinoma in situ, and invasive malignancy. Indeed, the concept of a field change in populations of epithelial cells is increasingly accepted. ${ }^{1011}$ In the case of lung cancer occurrence of a second (metachronous) primary malignant lung neoplasm has been described in over $10 \%$ of patients surviving for three or more years. ${ }^{212}$ Reports of synchronous carcinomas in the lung are fewer, amounting to less than $1 \%$ of cases in most series. ${ }^{34}$ The reported cases

Table Clinical and pathological data on 19 patients with synchronous pulmonary carcinoma

\begin{tabular}{|c|c|c|c|c|c|c|}
\hline No/Case & $\begin{array}{l}\text { Sex, } \\
\operatorname{age}(y)\end{array}$ & $\begin{array}{l}\text { Origin of } \\
\text { specimen }\end{array}$ & Histological type and TNM stage ${ }^{9}$ & $\begin{array}{l}\text { Smoking } \\
\text { (cigarettes/day) }\end{array}$ & $\begin{array}{l}\text { Survival } \\
\text { (months) }\end{array}$ & $\begin{array}{l}\text { Cause of } \\
\text { death }\end{array}$ \\
\hline 1 & M,46 & RUL & Squamous $\left(\mathrm{T}_{2} \mathrm{~N}_{0}\right) /$ adeno $\left(\mathrm{T}_{1} \mathrm{~N}_{1}\right)$ & 30 & 5 & Tumour \\
\hline 2 & $\mathrm{~F}, 63$ & LL & $\begin{array}{l}\text { Squamous }\left(\mathrm{T}_{3} \mathrm{~N}_{1}\right) / \\
\quad \text { atypical carcinoid }\left(\mathrm{T}_{1} \mathrm{~N}_{0}\right.\end{array}$ & 30 & 4 & Tumour \\
\hline 3 & $\mathbf{M}, 70$ & $\mathrm{RU}+\mathrm{ML}$ & Squamous $\left(\mathrm{T}_{2} \mathrm{~N}_{0}\right) /$ adeno $\left(\mathrm{T}_{2} \mathrm{~N}_{0}\right)$ & 40 & 9 & Tumour \\
\hline 4 & M,57 & LL & Squamous $\left(\mathrm{T}_{2} \mathrm{~N}_{2}\right) /$ adeno $\left(\mathrm{T}_{2} \mathrm{~N}_{0}\right)$ & 20 & 9 & Tumour \\
\hline 5 & M,70 & $\overline{R L}$ & Squamous $\left(\mathrm{T}_{2} \mathrm{~N}_{2} /\right.$ squamous $\left(\mathrm{T}_{2} \mathrm{~N}_{0}\right)$ & None & 44 & $\begin{array}{l}\text { Myocardial } \\
\text { infarct }\end{array}$ \\
\hline 6 & M,63 & RL & Squamous $\left(T_{2} N_{0}\right) /$ small cell $\left(T_{1} N_{0}\right)$ & 40 & 11 & Tumour \\
\hline 7 & M,59 & LUL & Adeno $\left(\mathrm{T}_{2} \mathrm{~N}_{0}\right)$ /squamous $\left(\mathrm{T}_{1} \mathrm{~N}_{0}\right)$ & 20 & 13 & Tumour \\
\hline 8 & M,53 & RL & Squamous $\left(\mathrm{T}_{2} \mathrm{~N}_{1}\right)$ /squamous $\left(\mathrm{T}_{2} \mathrm{~N}_{0}\right)$ & $40^{\star}$ & 100 & $\begin{array}{l}\text { Myocardial } \\
\text { infarct }\end{array}$ \\
\hline 9 & $\mathbf{M}, 70$ & LL & $\begin{array}{l}\text { Atypical carcinoid }\left(T_{2} N_{1}\right) / \\
\text { squamous }\left(T_{1} N_{0}\right)\end{array}$ & 20 & 17 & Tumour \\
\hline 10 & $F, 69$ & RUL & Squamous $\left(\mathrm{T}_{2} \mathrm{~N}_{1}\right) /$ adeno $\left(\mathrm{T}_{1} \mathrm{~N}_{1}\right)$ & 15 & 38 & Tumour \\
\hline 11 & $M, 60$ & LL & Squamous $\left(\mathrm{T}_{2} \mathrm{~N}_{1}\right) /$ squamous $\left(\mathrm{T}_{2} \mathrm{~N}_{0}\right)$ & 20 & 42 & Tumour \\
\hline 12 & $\mathrm{~F}, 68$ & RLL & Squamous $\left(\times 3, T_{2}, T_{1}, T_{1} N_{0}\right)$ & 12 & PO & - \\
\hline 13 & M,74 & LL & Squamous $\left(\mathrm{T}_{3} \mathrm{~N}_{1}\right) /$ small cell $\left(\mathrm{T}_{3} \mathrm{~N}_{1}\right)$ & 20 & 20 & Tumour \\
\hline 14 & $M, 73$ & LUL & Squamous $\left(\mathrm{T}_{3} \mathrm{~N}_{0}\right) /$ small cell $\left(\mathrm{T}_{3} \mathrm{~N}_{0}\right)$ & 10 & 42 & $\begin{array}{l}\text { Myocardial } \\
\text { infarct }\end{array}$ \\
\hline 15 & $M, 62$ & $\mathrm{RU}+\mathrm{ML}$ & Squamous $\left(T_{1} N_{1}\right)$ /squamous $\left(T_{1} N_{0}\right)$ & $15^{\star}$ & 46 & Pneumonia \\
\hline 16 & M,74 & RUL & Squamous $\left(\mathrm{T}_{2} \mathrm{~N}_{0}\right) /$ squamous $\left(\mathrm{T}_{2} \mathrm{~N}_{0}\right)$ & Unknown & 15 & Tumour \\
\hline 17 & $M, 72$ & LL & Squamous $\left(\mathrm{T}_{2} \mathrm{~N}_{1}\right)$ /squamous $\left(\mathrm{T}_{1} \mathrm{~N}_{0}\right)$ & 30 & 48 & Pneumonia \\
\hline 18 & M,73 & $\mathbf{L L}$ & Squamous $\left(T_{3} N_{2}\right) /$ adeno $\left(T_{1} N_{1}\right)$ & Pipe & PO & - \\
\hline 19 & $\mathrm{~F}, 63$ & RL & $\begin{array}{l}\text { Adenosquamous }\left(T_{2} N_{1}\right) / \\
\text { carcinoid }\left(T_{1} N_{0}\right)\end{array}$ & 20 & 8 & Tumour \\
\hline
\end{tabular}

*Stopped smoking at least two years before surgery. RL-right lung; LL-left lung; RUL-right upper lobe; LUL-left upper lobe; RLL_right lower lobe; RU + ML—right upper and middle lobes; PO-perioperative death. 
have come to light in various ways, both radiographically (presentation with obvious dual lesions ${ }^{13}$ ) and pathologically (either from surgical material or in the course of postmortem studies ${ }^{13-5}$ ). The aim of the present study was to ascertain the prevalence of synchronous tumours solely in the context of surgical material and to determine the effect of such a finding on survival.

The criteria for diagnosis of synchronous tumours in the lung vary from study to study. All authors agree that a clear plane of separation between tumour masses is essential. Similarly, the coexistence of discrete tumour masses of different histological subtypes is widely accepted as evidence of separate origins. Many authors exclude cases in which there is more than one tumour of a given histological type, arguing that the second tumour cannot reliably be distinguished from an intrapulmonary metastasis. Although this is indeed often the case we agree with Martini and Melamed ${ }^{3}$ that distinct squamous carcinomas can often be distinguished by identifying separate origins from areas of carcinoma in situ. The advent of DNA flow cytometry has introduced the possibility of further distinguishing such tumours by detecting tumour differences between tumours in DNA stemlines. This technique has been shown to be of use in renal as well as in pulmonary carcinomas. ${ }^{14-16}$

The incidence of synchronous carcinomas in the lung, as defined by the above criteria, is just under $2 \%$ of all cases coming to surgery in Edinburgh. As the pneumonectomy or lobectomy specimens examined in each case can never represent more than about half of the patient's lung tissue this figure is likely to underestimate the true incidence of synchronous tumours in the general population presenting with lung cancer. In this regard it is worth noting that the age and sex distribution of the patients included in this study, their smoking histories and the chest radiographs at presentation were not remarkable. That none of the patients had a preoperative radiological diagnosis of possible synchronous tumours may reflect an inclination among physicians not to refer patients with more than one pulmonary lesion for surgical resection. It is therefore perhaps not surprising that in the 18 cases where accurate tumour measurements were available the smaller tumour was staged as $\mathrm{T} 1$ in 11 cases $(62 \%)$. Most of these lesions measured no more than $1 \mathrm{~cm}$ (maximum diameter)

All of the patients were followed to their deaths. The overall prognosis for the group was dismal, with a $41 \%(7 / 17)$ three year and $6 \%(1 / 17)$ five year survival-even though only two patients had mediastinal node affected (N2 disease) at the time of resection. The adverse prognosis is in keeping with a previously published account by Deschamps et al from the Mayo Clinic, ${ }^{4}$ who observed that patients presenting with synchronous carcinomas had a worse prognosis than those patients having second resections for metachronous tumours developing after an initial non-small cell lung cancer had been treated surgically.

Perhaps the most important result to come out of our study is the finding that the generally bleak outlook for patients found to have synchronous primary pulmonary neoplasms does not appear to apply to those having carcinomas all of squamous type. This difference is statistically significant despite the small numbers. The better prognosis in patients with synchronous squamous tumours is in keeping with the generally acknowledged more favourable outlook for lung tumours of squamous type. In fact, most of the patients with synchronous squamous carcinomas died without evidence of tumour recurrence. We conclude that the pathologist's detection of more than one primary carcinoma in surgical resection specimens from patients with lung cancer is an indicator of poor prognosis except in patients presenting with multiple squamous carcinomas, when a somewhat less guarded prognosis would seem appropriate.

1 Abbey Smith R, Nigom BK, Thompson JM. Second primary lung carcinoma. Thorax 1976;31:507-16.

2 Johnson BE, Ihde DC, Matthews MJ, Bunn PA, Zabell A, Makuch RW, et al. Non-small cell lung cancer. Major cause of mortality in patients with small cell lung cancer. Am f Med 1986;80:1103-10.

3 Martini MD, Melamed MR. Multiple primary lung cancers. F Thorac Cardiovasc Surg 1975;70:606-11.

4 Deschamps C, Pairolero PC, Trastek VF, Payne WS. Multiple primary lung cancers. Results of surgical treatment. F Thorac Cardiovasc Surg 1990;99:769-78.

5 Jung-Legg Y, McGowan SE, Sweeney KG, Zitzman JL, Pugatch RD. Synchronous triple malignant tumours of the lung. A case report of bronchial carcinoid, small cell carcinoma and adenocarcinoma of the right lung. $A m \mathcal{F}$ Clin Pathol 1986;85:96-101.

6 Hedley DW, Friedlander ML, Taylor IW, Rugg CA, Musgrove EA. Method for analysis of cellular DNA content of paraffin-embedded pathological material using flow cytometry. F Histochem Cytochem 1983;31: 1333-5.

7 Carey FA, Lamb D, Bird CC. Importance of sampling method in DNA analysis of lung cancer. $f$ Clin Pathol 1990;43:820-3

8 Edinburgh Lung Cancer Group. Patients presenting with lung cancer in South-East Scotland. Thorax 1987;42: 853-7.

9 Mountain CF. A new international staging system for lung cancer. Chest 1986;89 (suppl):225-33S.

10 Kakizoe T, Matumoto $K$, Nishio $Y$, Ohtoni M, Kishli $K$. Significance of carcinoma in situ and dysplasia in association with bladder cancer. $\mathcal{F}$ Urol 1985;133:395-8.

11 Bauer WC, McGavron MH. Carcinoma in situ and evaluation of epithelial changes in laryngo-pharyngeal biopsies. $¥ A M A 1972 ; 221: 72-5$

12 Van Bodegom PC, Wagenaar SS, Corrin B, Baak JPA, Berkel J, Vanderschueren RGJ. Second primary lung
cancer: importance of long term follow up. Thorax cancer: importance

13 Caceras J, Felson B. Double primary carcinomas of the lung. Radiology 1972;102:45-50.

14 Banner BF, Brancazio L, Bahnson RR, Ernstaff MS, Taylor SR. DNA analysis of multiple synchronous renal cell carcinomas. Cancer 1990;66:2180-5.

15 Ichinosa Y, Hara N, Ohta M, Kuda T, Asoh H, Chikama H. DNA ploidy patterns of tumors diagnosed as metachronous or recurrent lung cancers. Ann Thorac Surg 1991;52:469-73.

16 Ichinosa Y, Hara N, Ohta M. Synchronous lung cancers defined by deoxyribonucleic acid flow cytometry. f Thorac Cardiovasc Surg 1991;102:418-24. 